Submitted to Experimental Mechanics, December 2000

Revised, September 2001

\title{
Analysis of a Multiaxial Test on a $C / C$ composite by Using Digital Image Correlation and a Damage Model
}

\author{
by \\ Jean-Noël PÉRIÉ, Sylvain CALLOCH, ${ }^{*}$ Christophe CLUZEL and François HILD \\ LMT-Cachan \\ ENS de Cachan / CNRS-UMR 8535 / Université Paris 6 \\ 61, avenue du Président Wilson, F-94235 Cachan Cedex, France
}

* To whom correspondence should be addressed

Fax: +33 1474022 40, Email: calloch@1mt.ens-cachan.fr 


\title{
Analysis of a Multiaxial Test on a $\mathrm{C} / \mathrm{C}$ composite by Using Digital Image Correlation and a Damage Model
}

\author{
by \\ Jean-Noël PÉRIÉ, Sylvain CALLOCH, Christophe CLUZEL and François HILD
}

\begin{abstract}
The 'planar' digital image correlation technique needs a single CCD camera to acquire the surface patterns of a zone of a specimen in the undeformed and deformed states. With these two images, one can determine in-plane displacement and strain fields. The digital image correlation technique used herein is based on Fast Fourier Transforms, which are very effective in reducing the computation cost. Its performance is assessed and discussed on artificial signals and in a real experimental situation. The technique is utilized to analyze experimental results of a plane shear experiment and validate a damage meso-model describing different degradations in a $\mathrm{C} / \mathrm{C}$ composite material.
\end{abstract}




\section{INTRODUCTION}

With the development of complex thermomechanical experiments, displacement and strain field measurements are often needed (e.g., strain localization in materials, ${ }^{1}$ strain concentrations around edges and notches, ${ }^{2}$ strain and displacement singularities in cracked bodies $^{3,4}$ ). High temperature tests are very demanding on conventional strain measurements (i.e., the use of an extensometer is usually the unique solution). Other applications concern soft solids, not to mention fluids, where strain gauges may be difficult to position (e.g., glass wool, ${ }^{5}$ paper and wood, ${ }^{6}$ polymers $\left.{ }^{7,8}\right)$. In recent years, the development of efficient tools for full-field velocimetry, specially designed in the context of fluid flows, has been quite important, and the fast evolving capabilities of digital image acquisition and software for image analysis prompts us to resort to such techniques for full-field displacement measurements. Particle Imaging Velocimetry (PIV) $)^{9,10}$ has proven to be a very efficient tool with very robust capacities in the context of fluid flow visualization. ${ }^{11}$

These techniques can also be adapted to evaluate $2 \mathrm{D}$ or $3 \mathrm{D}$ displacement fields of the surface of solids. On the one hand, the experiments can be performed with a controlled illumination device (i.e., laser) for which holographic or shearing interferometry, ESPI and laser speckle photography are some means. ${ }^{12}$ These techniques often require careful preparations and are not always suitable for experiments in a conventional testing lab. On the other hand, white light can also be used in fringe projection methods as well as moiré or speckle photography. For the latter, by acquiring pictures for different load levels and using one Charge-Coupled Device (CCD) camera, it is possible to determine the in-plane displacement field by matching different zones of two pictures. The simplest image-matching procedure is cross-correlation that can be performed either in the physical space ${ }^{13-16}$ or in Fourier space. ${ }^{17-19}$ It consists in looking for the maximum correlation between small zones in the deformed and reference images. The translation, which corresponds to the maximum correlation, can thus be extracted for different positions of the zone of interest. The extensive use of Fast Fourier Transforms (FFT) is very effective in reducing the computation cost.

Digital Image Correlation (DIC) techniques can be used under various circumstances. First, it is useful in controlling a priori the actual boundary conditions (e.g., their uniformity in a biaxial compression test on shape memory alloys was improved by using this technique ${ }^{20}$ ). 
Second, the inception of localized phenomena can be monitored accurately (e.g., strain concentrations in composites, ${ }^{21}$ necking in metals, ${ }^{22}$ crack initiation in different materials ${ }^{23}$ ). More generally, full-field measurements constitute an opportunity to bridge the gap between experiments and simulations allowing for comparisons between measured and computed displacement and strain fields. The aim of the paper is to show how the DIC technique can be used to validate a damage model in a multiaxial experiment for which the strain field is, by essence, heterogeneous. Section 2 is devoted to the presentation of the correlation technique used herein. The basic tools of the method are introduced. The algorithm is then discussed. Its performance is assessed with artificial 1D signals and 2D images. Section 3 deals with an application of the digital image correlation technique under multiaxial loading conditions. First, a damage model to be validated is introduced. The geometry of a specimen loaded in shear is designed by using the afore-mentioned damage model. The testing machine and its control system are presented. The performance of the technique is then evaluated in the shear experiment on a $\mathrm{C} / \mathrm{C}$ composite material. A comparison between experiments and simulations by using the damage meso-model is performed. Two possible strategies are compared to couple displacement field measurements with finite element simulations.

\section{DISPLACEMENT AND STRAIN FIELD MEASUREMENTS}

The displacement and strain fields are determined by digital image correlation. By using a CCD camera, pictures at different stages are recorded during the test. The specimen is usually coated by a random black and white pattern. Sometimes the natural texture of the observed surface is sufficient to use the technique with no coating. The in-plane displacement map is computed with a correlation technique between an initial picture and a subsequent one.

\subsection{Preliminaries: Image Correlation}

One considers a sequence of sub-images (i.e., a square region) which will be referred to as zone of interest (ZOI). The aim of correlation method is to match the zone of interest in the two images (Fig. 1). The displacement of one ZOI with respect to the other one is a two-dimensional shift of an intensity signal digitized by a CCD camera. To estimate a shift between two images, 
one of the standard approaches utilizes a correlation function. One considers signals $\mathrm{g}(\xi, \psi)$ which are merely perturbations of a shifted copy $\mathrm{f}\left(\xi-\delta_{\mathrm{x}}, \psi-\delta_{\mathrm{y}}\right)$ of some reference signal $\mathrm{f}(\xi, \psi)$

$$
\mathrm{g}(\xi, \psi)=\mathrm{f}\left(\xi-\delta_{\mathrm{x}}, \psi-\delta_{\mathrm{y}}\right)+\mathrm{b}(\xi, \psi)
$$

where $\delta_{\mathrm{x}}, \delta_{\mathrm{y}}$ are unknown displacements and $\mathrm{b}(\xi, \psi)$ a random noise. To evaluate the shift $\left(\delta_{\mathrm{x}}, \delta_{\mathrm{y}}\right.$ ), one may minimize the norm of the difference between $f(\xi-x, \psi-y)$ and $g(\xi, \psi)$ with respect to $x$ and $\mathrm{y}$

$$
\min _{\mathrm{x}, \mathrm{y}}\|\mathrm{g}-\mathrm{f}(.-\mathrm{x}, .-\mathrm{y})\|^{2} .
$$

where ' ' denotes a dummy parameter. If one chooses the usual quadratic norm If $\|^{2}=\int_{-\infty-\infty}^{+\infty+\infty} f(\xi, \psi) d \xi d \psi$, the previous minimization problem is equivalent to maximizing the quantity $h(x, y)$

$$
h(x, y)=(g * f)(x, y)=\int_{-\infty-\infty}^{+\infty+\infty} g(\xi, \psi) f(\xi-x, \psi-y) d \xi d \psi
$$

where $*$ denotes the cross-correlation operator. Furthermore, when $\mathrm{b}$ is a white noise, the previous estimate is optimal. The computation of a cross-correlation can be performed either in the original space or in Fourier space, by using an FFT

$$
\mathrm{g} * \mathrm{f}=\mathrm{FFT}^{-1}(\mathrm{FFT}[\mathrm{g}] \overline{\mathrm{FFT}[\mathrm{f}]})
$$

where the complex conjugate is overlined. The use of the 'shifting' property enables one to 'move' a signal. For the sake of simplicity, let us consider the shift operator $T_{d}$ defined for 1D signals and defined by

$$
\left[T_{d} f\right](\xi)=f(\xi-d)
$$

where $d$ is the shift parameter. The FFT of $T_{d} f$ becomes

$$
\operatorname{FFT}\left[T_{d} f\right]=E_{d} \operatorname{FFT}[f]
$$


where the modulation operator $\mathrm{E}_{\mathrm{d}}$ is defined by

$$
\left[E_{d} f\right](\xi)=\exp (-2 \pi j d \xi) f(\xi)
$$

These two results constitute the basic tools for image correlation.

\subsection{Correlation Algorithm for Two-Dimensional Signals: CORRELI ${ }^{2 D}$}

Two images are considered. The first one, referred to as 'reference image' and the second one, called 'deformed image.' Figure 2 shows the algorithm explained below. One extracts the largest value $\mathrm{p}$ of a region of interest (ROI) of size $2^{\mathrm{p}} \times 2^{\mathrm{p}}$ pixels centered in the reference image. The same ROI is considered in the deformed image. A first FFT correlation is performed to determine the average displacement $\mathrm{U}_{0}, \mathrm{~V}_{0}$ of the deformed image with respect to the reference image. This displacement is expressed in an integer number of pixels and is obtained as the maximum of the cross-correlation function evaluated for each pixel of the ROI. This first prediction enables one to determine the maximum number of pixels that belong to the two images. The ROI in the deformed image is now centered at a point corresponding to displaced center of the ROI in the reference image by an amount $\mathrm{U}_{0}, \mathrm{~V}_{0}$.

The user usually chooses the size of the zones of interest (ZOI) by setting the value of $\mathrm{s}<$ p so that the size is $2^{\mathrm{S}} \times 2^{\mathrm{S}}$ pixels. To map the whole image, the second parameter to choose is the shift $\delta \mathrm{x}(=\delta \mathrm{y})$ between two consecutive ZOIs: $1 \leq \delta \mathrm{x} \leq 2^{\mathrm{S}}$ pixels. These two parameters define the mesh formed by the centers of each ZOI used to analyze the displacement field. The following analysis is performed for each ZOI independently. It follows that parallel computations can be used in the present case. A first FFT correlation is carried out and a first value of the inplane displacement correction $\Delta \mathrm{U}, \Delta \mathrm{V}$ is obtained. The values $\Delta \mathrm{U}, \Delta \mathrm{V}$ are again integer numbers so that the ZOI in the deformed image can be displaced by an additional amount $\Delta \mathrm{U}, \Delta \mathrm{V}$. The displacement residues are now less than $1 / 2$ pixel in each direction. A sub-pixel iterative scheme can be used.

To get good localization properties of the Fourier transform, the considered ZOI is then windowed by a modified Hanning window

$$
\underline{\mathrm{ZOI}}=\mathrm{ZOI}(\mathrm{H} \otimes \mathrm{H})
$$


where $\underline{\mathrm{ZOI}}$ denotes the windowed $\mathrm{ZOI}, \otimes$ the dyadic product and $\mathrm{H}$ the one-dimensional modified Hanning window

$$
H(i)= \begin{cases}\frac{1}{2}\left[1-\cos \left(\frac{4 \pi i}{2^{s}-1}\right)\right] & \text { when } 0 \leq \mathrm{i} \leq 2^{\mathrm{s}-2} \\ 1 & \text { when } 2^{\mathrm{s}-2} \leq \mathrm{i} \leq 3 \times 2^{\mathrm{s}-2} \\ \frac{1}{2}\left[1-\cos \left(\frac{4 \pi \mathrm{i}}{2^{\mathrm{s}}-1}\right)\right] & \text { when } 3 \times 2^{\mathrm{s}-2} \leq \mathrm{i} \leq 2^{\mathrm{s}}-1\end{cases}
$$

The value $2^{\mathrm{s}-2}$ is an optimal value ${ }^{24}$ to minimize the error due to edge effects and to have a sufficiently large number of data unaltered by the window. A cross-correlation is performed. A sub-pixel correction of the displacement $\delta \mathrm{U}, \delta \mathrm{V}$ is obtained by determining the maximum of a parabolic interpolation of the correlation function. The interpolation is performed by considering the maximum pixel and its eight nearest neighbors. Therefore, one obtains a sub-pixel value. By using the 'shifting' property of the Fourier transform, one can move the deformed ZOI by an amount $-\delta U,-\delta V$. Since an interpolation was used, one may induce some errors requiring to reiterate by considering the new 'deformed' ZOI until a convergence criterion is reached. The criterion checks whether the maximum of the interpolated correlation function increases as the number of iteration increases. Otherwise, the iteration scheme is stopped. The procedure, ${ }^{24}$ CORRELI $^{2 \mathrm{D}}$, is implemented in Matlab ${ }^{\mathrm{TM}}{ }^{25}$

\subsection{Performance of the Algorithm}

The first results are analyzed for 1D synthetic signals. A random pattern is generated (it is based on a Poisson Point Process for the center of segments of size equal to 5 pixels ${ }^{24}$ ) and a second displaced signal is created with no noise (see Eqn. (2) with $b=0$ ). However, digitization is accounted for and the whole scale is used. In many practical situations, CCD cameras produce 8bit pictures. Some more sophisticated ones lead to 10-bit, 12-bit or even 16-bit codings. Let us first assume that the analyzed signal is 8 -bit coded. Consequently, any displacement less than $2^{-8}$ pixel cannot be observed by an 8-bit camera (i.e., no grey level variation is obtained). Figure 3 shows the change in average relative error between a prescribed and measured displacement as a function of the prescribed displacement. Above the minimum observable value, the average 
relative error is of the order of $3.5 \%$ for any value of the displacement. The minimum measurable displacements become smaller as the number of bits increases. Figure 3 illustrates this phenomenon. A lower bound is given by $2^{-b}$ pixel, for a b-bit signal. Therefore, if the measurement of small displacements and strains is an issue, CCD cameras with high values of $b$ are recommended. Furthermore, the variation of brightness and contrast may lead to an artificial change in coding. Instead of using the whole range of the coding, only a fraction is actually used. Consequently, the average error in displacement is digitization-independent (see Fig. 3). However, the minimum detectable displacement is strongly dependent upon the coding range.

The previous results have a direct influence on the measurable strains. The strain measurement is performed by considering two adjacent centers of ZOI (a distance $\delta \mathrm{x}$ apart) and the displacement derivative is then evaluated. In that case, an estimate of the minimum measurable strain $\varepsilon_{\min }$ (assumed to be constant over the gauge length) is directly related to the minimum detectable displacement increment $u_{\min }$ for one fifth of the gauge length

$$
\varepsilon_{\min } \approx 5 \frac{\mathrm{u}_{\min }}{\mathrm{L}}
$$

where $\mathrm{L}$ denotes the gauge length (i.e., the maximum distance between the centers of the ZOI). This result is consistent with numerical simulations for which values as low as $10^{-5}$ could be achieved when the gauge length was on the order of 1000 pixels and 64 ZOI where analyzed ${ }^{24}(\mathrm{~s}$ $=6, \delta x=64$ pixels). Equation (10) shows that to detect very small strains, one needs to increase the size of the gauge length, which may prevent one from detecting fluctuations or even discontinuities. A good compromise for 1024-pixel signals is a 32- to 64-pixel long ZOI. For an 8-bit camera, these values are mainly indications of the general performances of the correlation algorithm. The procedure is now used with real images for which noise has to be considered (e.g., photon noise, readout noise, dark current or thermal noise ${ }^{26}$ ) as well as digitization.

Figure 4 shows the sub-pixel measurements obtained by the correlation technique. The $\mathrm{C} / \mathrm{C}$ composite specimen to be introduced in Section 3.2 was used. The surface was sprayed by B/W paint to obtain a random texture (Fig. 10a). The sample was moved with a micrometric screw and the displacement was measured by an LVDT (maximum range: $\pm 3 \mu \mathrm{m}$ ). Because of a mean absolute error less than 3/100-th pixel, ${ }^{24}$ displacements less than the latter cannot be 
measured accurately. This value has to be augmented by about $1 / 100$-th pixel to account for digitization errors (since the full-scale of digitization is almost never achieved). It follows that the results of Fig. 4 are in agreement with the previous prediction. In the present case, displacements as small as $1 \mu \mathrm{m}$ can be measured with a very good accuracy, since the order of magnitude of the minimum displacement is $0.5 \mu \mathrm{m}$.

In Fig. 5, strain measurements by using strain gauges are compared with predictions of the correlation technique. Longitudinal and transverse strains are evaluated in a tensile test of a 2024 aluminum alloy specimen. A special set-up is used to avoid spurious flexure. ${ }^{27-28}$ A long-distance microscope is utilized to monitor a surface of $4 \mathrm{~mm}^{2}$. The average strain is computed over the total observed surface (i.e., 1008 x 1016 pixels). First, the displacement field is interpolated by cubic B-spline functions. The strain field is then derived and the average is computed. As expected, it is shown that a ZOI size of 64 pixels leads to better results than that with 32 pixels. The average absolute error is less than $510^{-5}$ in the first case and $7.610^{-5}$ in the second case. Strains as small as $510^{-5}$ can be measured accurately in the first case and $10^{-4}$ in the second case. Furthermore, it can be noted that the average shear strains (negligibly small with the set-up) are found to be equal to $-810^{-7}$ and $10^{-5}$, respectively, with an average absolute error $2.510^{-5}$ and $3.810^{-5}$, respectively. In Section 3.2, the same analysis will be performed when the strain field is heterogeneous.

When a sequence of more than two images is analyzed, two routes can be followed. The first one consists in considering the same reference image. It follows that the errors are not cumulated but there exists a maximum strain level above which the method fails. For a ZOI of 64 pixels, the maximum observable strain is of the order of 5\% for a 1 Mpixel image. The second one considers that the reference image is the deformed image of the previous step so that the displacements are added. Under these hypotheses, there is no real limitation, apart from the fact that the errors are now cumulated, and strains higher than $100 \%$ are routinely observed in a fullfield assessment. ${ }^{8}$

\section{USE OF FULL-FIELD MEASUREMENTS TO ANALYZE A MULTIAXIAL TEST}

The aim of this part is to validate a damage model by using a multiaxial test. Instead of assuming (perfect) boundary conditions, the displacement field measured by the DIC technique is used as an input for the FE simulations. 


\subsection{Damage Meso-Model}

A biaxial test is developed within the context of the modeling of the mechanical behavior

of Multirex ${ }^{\circledR}$ materials submitted to complex loading conditions. Multirex ${ }^{\circledR}$ materials are carbon/carbon composites manufactured by SNECMA Engine Division. ${ }^{29}$ Multirex ${ }^{\circledR}$ preforms are either planar or axisymmetric. They are obtained by stacking either unidirectional plies or satin layers made of carbon yarns. Yarn fibers can be continuous or discontinuous. A needling process transfers some fibers along the third direction, perpendicular to the layer (Fig. 6a). These fiber reinforcements forbid delamination propagation. A Chemical Vapor Infiltration deposits the matrix in the preform made of discontinuous fibers. This type of material is specially designed for thermostructural applications such as brakes or structural parts of a rocket engine. The investigation concerning the thermomechanical behavior of a $\mathrm{C} / \mathrm{C}$ composite focuses first on a series of uniaxial tension and compression tests in different directions on a $[0,90]_{\mathrm{n}}$ satin composite. These tests show an anisotropic behavior with damage and inelastic strains for tensile tests at $0^{\circ}$ and $\pm 45^{\circ}$. A different damage kinetics between tension and compression in both loading directions has been observed. ${ }^{30}$

Constitutive equations based on an anisotropic damage model ${ }^{31}$ written on a meso scale (i.e., that of a ply) is used to describe the main degradation mechanisms. ${ }^{29,32}$ The model is based on the laminate theory and accounts for non linearities in each ply. Because the laminate thickness is negligible in comparison with other dimensions, a state of plane stress and a Kirchhoff-Love kinematics are assumed. Satin plies are modeled by a stacking of two orthogonal unidirectional elementary plies made of non-continuous fibers. For each ply, the degradation is assumed to be anisotropic and dictated by the fiber direction. Therefore, the damage meso-model is written in the ply coordinate system (1: fiber direction; 2: transverse direction). The elastic behavior of the $\mathrm{i}^{\text {th }}$ ply can be written as

$$
\underline{\hat{\varepsilon}}_{\mathrm{i}}^{\mathrm{e}}=\underline{\hat{K}}_{\mathrm{i}}^{-1} \underline{\hat{\sigma}}_{\mathrm{i}}
$$

with 


$$
\hat{\underline{\underline{\sigma}}}_{i}=\left[\begin{array}{c}
\sigma_{11} \\
\sigma_{22} \\
\sqrt{2} \sigma_{12}
\end{array}\right], \underline{\hat{\underline{\varepsilon}}}_{i}^{e}=\left[\begin{array}{c}
\varepsilon_{11}^{e} \\
\varepsilon_{22}^{e} \\
\sqrt{2} \varepsilon_{12}^{e}
\end{array}\right], \underline{\underline{\hat{K}}}_{i}^{-1}=\left[\begin{array}{ccc}
\frac{1}{E_{1}^{0}} & \frac{-v_{12}^{0}}{E_{1}^{0}} & 0 \\
-v_{12}^{0} & \frac{1}{E_{2}^{0}} & 0 \\
E_{1}^{0} & \\
0 & 0 & \frac{1}{2 G_{12}^{0}}
\end{array}\right]
$$

where $\hat{\underline{\varepsilon}}_{i}^{e}$ is the elastic strain tensor in Voigt's notations, $\underline{\hat{\sigma}}_{i}$ the corresponding in-plane stress tensor, and $\underline{\underline{\underline{K}}}_{\mathrm{i}}$ the stiffness tensor expressed here as a function of the initial elastic properties of the material (denoted by the exponent ${ }^{0}$ ). For layers made of continuous fibers, the same framework has been used to model the mechanical behavior of laminates such as carbon/epoxy ${ }^{29}$ or carbon/ carbon $^{33}$ composites. For layers with non-continuous fibers, an additional damage variable $\left(d_{1}\right)$ is introduced in the fiber direction to describe stiffness loss in that direction. ${ }^{34}$ Such models are able to predict a degradation distribution for various configurations. ${ }^{30}$ Damage kinetics is then described by using the elastic energy density of the damaged layer. For a plane stress state, this energy density $E_{d}$ can be written as

$$
\mathrm{E}_{\mathrm{d}}=\frac{1}{2}\left\{\frac{\left\langle\sigma_{11}\right\rangle_{+}^{2}}{\mathrm{E}_{1}^{0}\left(1-\mathrm{d}_{1}\right)}+\frac{\left\langle\sigma_{11}\right\rangle_{-}^{2}}{\mathrm{E}_{1}^{0}}+\frac{\left\langle\sigma_{22}\right\rangle_{+}^{2}}{\mathrm{E}_{2}^{0}\left(1-\mathrm{d}_{2}\right)}+\frac{\left\langle\sigma_{22}\right\rangle_{-}^{2}}{\mathrm{E}_{2}^{0}}-2 \frac{v_{12}^{0}}{\mathrm{E}_{1}^{0}} \sigma_{11} \sigma_{22}+\frac{\sigma_{12}^{2}}{\mathrm{G}_{12}^{0}\left(1-\mathrm{d}_{12}\right)}\right\}
$$

with

$$
\begin{cases}\langle\mathrm{f}\rangle_{+}=\mathrm{f} \text { if } \mathrm{f} \geq 0,\langle\mathrm{f}\rangle_{+}=0 & \text { otherwise } \\ \langle\mathrm{f}\rangle_{-}=\mathrm{f} \text { if } \mathrm{f} \leq 0,\langle\mathrm{f}\rangle_{-}=0 & \text { otherwise }\end{cases}
$$

The damage variables $\left(d_{1}, d_{2}, d_{12}\right)$ are assumed to be piecewise constant within the different plies. The difference between tensile and compressive behavior is caused by the opening and closure of micro-cracks. This aspect is accounted for by splitting the elastic energies into a 'tensile' energy $\left(\langle.\rangle_{+}\right)$and a 'compressive' energy ( $\left.\langle.\rangle_{-}\right)$. The kinetic laws of the damage variables $\mathrm{d}_{1}, \mathrm{~d}_{12}$ et $\mathrm{d}_{2}$ are written as 


$$
\begin{aligned}
& d_{1}(t)=d_{1}\left(Y_{d_{1}}(\tau), Y_{d_{12}}(\tau), Y_{d_{2}}(\tau), \tau \leq t\right) \\
& d_{12}(t)=d_{12}\left(Y_{d_{1}}(\tau), Y_{d_{12}}(\tau), Y_{d_{2}}(\tau), \tau \leq t\right) \\
& d_{2}(t)=d_{2}\left(Y_{d_{1}}(\tau), Y_{d_{12}}(\tau), Y_{d_{2}}(\tau), \tau \leq t\right)
\end{aligned}
$$

where $\mathrm{Y}_{\mathrm{d} 1}, \mathrm{Y}_{\mathrm{d} 12}, \mathrm{Y}_{\mathrm{d} 2}$ are the corresponding thermodynamic forces

$$
\begin{aligned}
& Y_{d_{1}}=\left.\frac{\partial E_{d}}{\partial d_{1}}\right|_{\sigma}=\frac{\left\langle\sigma_{11}\right\rangle_{+}^{2}}{2 E_{1}^{0}\left(1-d_{1}\right)^{2}} \\
& Y_{d_{12}}=\left.\frac{\partial E_{d}}{\partial d_{12}}\right|_{\sigma}=\frac{\left(\sigma_{12}\right)^{2}}{2 G_{12}^{0}\left(1-d_{12}\right)^{2}} \\
& Y_{d_{2}}=\left.\frac{\partial E_{d}}{\partial d_{2}}\right|_{\sigma}=\frac{\left\langle\sigma_{22}\right\rangle_{+}^{2}}{2 E_{2}^{0}\left(1-d_{2}\right)^{2}}
\end{aligned}
$$

By following previous analyses, ${ }^{29}$ the kinetic laws for transverse damage $d_{2}$ and shear damage $d_{12}$ are governed by the same coupled force $Y_{d_{12}}+b Y_{d_{2}}$. Furthermore, the damage kinetics in the fiber direction $d_{1}$ is not coupled with transverse and shear damage

$$
\begin{aligned}
& d_{1}(t)=g\left(Y_{d_{1}}(\tau), \tau \leq t\right) \text { if } d_{1}<1, d_{1}=1 \text { otherwise } \\
& d_{12}(t)=g\left(Y_{d_{12}}(\tau)+b Y_{d_{2}}(\tau), \tau \leq t\right) \text { if } d_{12}<1, d_{12}=1 \text { otherwise } \\
& d_{2}(t)=b g\left(Y_{d_{12}}(\tau)+b Y_{d_{2}}(\tau), \tau \leq t\right) \text { if } d_{2}<1 \text { and } Y_{d_{2}}<Y_{d_{2}}^{\text {critical }}, d_{2}=1 \text { otherwise }
\end{aligned}
$$

As a first approximation, the functions $g$ and g' are assumed to be linear when written in terms of the square root of the driving forces $Y_{d_{1}}$ and $Y_{d_{12}}+b Y_{d_{2}}$, respectively

$$
g^{\prime}(Y)=\frac{\sqrt{Y}-\sqrt{Y_{0_{1}}}}{\sqrt{Y_{c_{1}}}} \text { and } g(Y)=\frac{\sqrt{Y}-\sqrt{Y_{0}}}{\sqrt{Y_{c}}}
$$

The load history can be taken into account by using the following relationships 


$$
\begin{aligned}
& Y_{d_{1}}(t)=\sup _{\tau \leq t} Y_{d_{1}}(\tau) \\
& Y_{d_{12}}(t)=\sup _{\tau \leq t} Y_{d_{12}}(\tau) \\
& Y_{d_{2}}(t)=\sup _{\tau \leq t} Y_{d_{2}}(\tau)
\end{aligned}
$$

Inelastic strains on the ply level are assumed to be related to frictional phenomena. They are described by a plasticity model with isotropic hardening. The coupling between inelastic strains and damage is performed by using effective strains $\underline{\tilde{\varepsilon}}$ and stresses $\underline{\tilde{\sigma}}$ defined by

$$
\operatorname{Tr}\left(\underline{\sigma} \cdot{\underline{\underline{\varepsilon^{\prime}}}}^{\prime}\right)=\operatorname{Tr}\left(\underline{\tilde{\sigma}} \cdot \underline{\underline{\varepsilon}}^{p}\right)
$$

with,

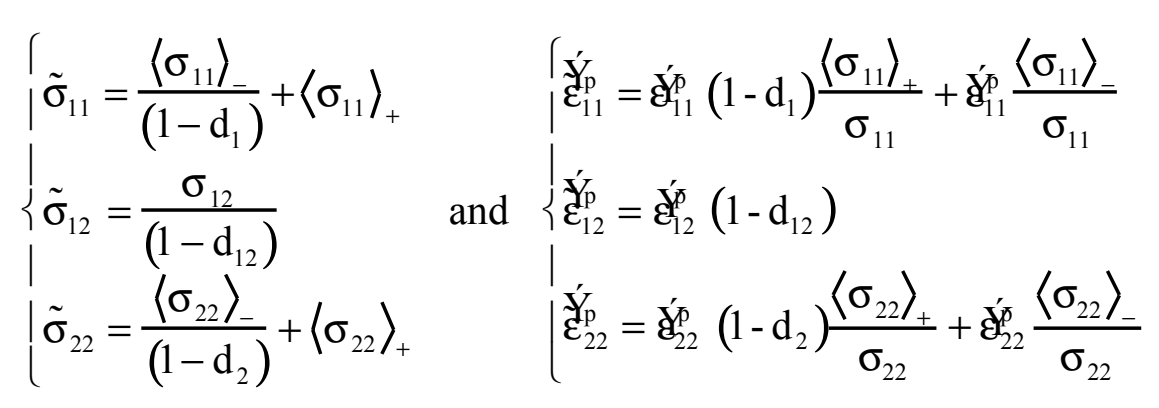

The yield surface is described by the following function

$$
\mathrm{f}(\underline{\tilde{\sigma}}, \mathrm{R})=\sqrt{\mathrm{a}_{11}^{2} \tilde{\sigma}_{11}^{2}+\mathrm{a}_{22}^{2} \tilde{\sigma}_{22}^{2}+\mathrm{a}_{12}^{2} \tilde{\sigma}_{12}^{2}}-\mathrm{R}(\mathrm{p})-\mathrm{R}_{0} \leq 0
$$

The plastic flow is given by

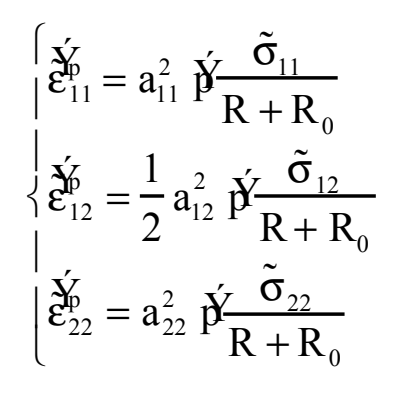

where 1 is the rate of cumulative plastic strain

$$
\dot{p}=\sqrt{a_{11}^{-2}\left(\hat{\varepsilon}_{11}^{\prime}\right)^{2}+4 a_{12}^{-2}\left(\hat{\varepsilon}_{12}^{\prime}\right)^{2}+a_{22}^{-2}\left(\frac{\hat{z}_{22}^{\prime}}{\varepsilon_{2}}\right)^{2}}
$$


A complete identification requires loading the plies in various directions. However, the number of sequences available for the material is limited. Consequently, the identification is restricted to the more significant terms of the strain energy. ${ }^{32}$ The identification is performed in two steps. First, elastic coefficients for both meso-constituents have been identified with tensile tests on a $[0,90]_{\mathrm{n}}$ hybrid composite made of both continuous and non-continuous fibers. Second, non-linear parameters have been identified thanks to tensile tests at $0^{\circ}$ and $\pm 45^{\circ}$ on a $[0,90]_{\mathrm{n}}$ satin composite made of non-continuous fibers. ${ }^{30}$ For each test, several loading/unloading cycles are performed to evaluate the damage parameters (i.e., stiffness loss) and inelastic strains. An ad hoc identification strategy has been used to determine the whole set of material parameters. ${ }^{35}$ The identified parameters are shown in Table 1 for a Multirex ${ }^{\circledR}$ material. These parameters are implemented in a damage post-processor. ${ }^{36}$ The input to the post-processor is the in-plane macroscopic strain tensor measured, by say a DIC technique, or the in-plane macroscopic stress tensor computed by a FE analysis. The Kirchhoff-Love kinematics yields strains or stresses on the ply level (i.e., meso level). The output is the dual macroscopic field (i.e., stress or strain, respectively) and the internal variables (e.g., damage) in each ply. The tensile tests performed on the $[0,90]_{\mathrm{n}}$ satin composite and used during the identification stage are simulated. Experimental and simulated strain/stress curves including various loading/unloading cycles are superimposed (Figure 7). The good agreement allows us to validate the tuning of the model parameters and the post-processor.

\subsection{Shear Experiment on a C/C Composite}

The previous constitutive equations need to be validated with experimental results that have not been used in the identification stage. This is the role of the biaxial test discussed herein. This test is simulated with a 2D Finite Element (FE) analysis by using the above-mentioned constitutive equations and post-processor. Different degradation mechanisms are modeled by the three damage variables $d_{1}, d_{2}$ and $d_{12}$. Consequently, if this model is realistic, it should allow for the determination of the onset of overall failure by computing various damage fields: a damage localization usually corresponds to macro-crack initiation. Therefore, the comparison between FE simulations and experimental results enables us to test the predictive capacity of the model to describe crack initiation and to determine which mechanism led to crack initiation. 
The test presented in this paper has been carried out on a multiaxial testing machine (ASTREE, see Fig. 8a). This testing machine has six servohydraulic actuators. Two vertical actuators, linked with the mobile crosshead and the base, respectively, have a load capacity of $250 \mathrm{kN}$ and a stroke range of $250 \mathrm{~mm}$. Four horizontal actuators have a load capacity of $100 \mathrm{kN}$ and a stroke range of $250 \mathrm{~mm}$. For protection purposes of the actuators at specimen failure (which can cause extremely high side and twist loads), additional hydraulic bearings are installed in front of each actuator. Closed loop control for each actuators is provided by a digital controller (Schenck 59 serial Hydropuls). The digital controller allows each actuator to be driven independently or in centroid mode. The centroid mode uses a relationship between two opposing actuators along the same axis to maintain the center of the specimen motionless. By ensuring that the center of the specimen and loading frame coincide, the user can prevent off-axis loadings that would damage the other actuators. Figure $8 \mathrm{~b}$ illustrates how the centroid control algorithms work for a load-controlled test. For each axis pair (e.g., Y+ Y-), the controller uses the sum of the forces and the difference of the displacements along the considered axis. The performance of the centroid mode has been evaluated by using the DIC technique and a cross-shaped specimen. The results show that the centroid mode maintained the center of the specimen within $\pm 10 \mu \mathrm{m}$ from its initial position (i.e., less than 1 pixel in each direction). This centroid mode has been used in the multiaxial test presented hereafter.

Tabs are glued on the face of each connecting arm of the specimen (Fig. 6b). The yarns are parallel to the bisectors of the loading directions. An a priori $\mathrm{FE}$ analysis of this geometry, using the above-mentioned damage model, shows that the shear damage field $\mathrm{d}_{12}$ is confined in the central part of the specimen (Fig. 9). Because of the initial anisotropy of the material with respect to the loading axes, the central part of the specimen is the most loaded zone in terms of damage $d_{12}$ as well as strains. ${ }^{32}$

Three strain gauges are glued on one face of the specimen, positioned at $0^{\circ}, 45^{\circ}$ and $90^{\circ}$, respectively (Fig. 10a). The strain field measurement is performed on the same face of the specimen. The specimen is maintained in the grips by $4 \times 8$ screws (Fig. 6b). For comparison purposes, the responses of two strain gauges (i.e., $0^{\circ}$ and $90^{\circ}$ ) are considered. Figure $10 \mathrm{~b}$ shows the gauge response and the average strain over the same active surface deduced from digital image correlation during the cyclic load history (Fig. 10c). A mean absolute error of $10^{-4}$ is obtained for this heterogeneous strain field. This result is consistent with the observations 
reported in Section 2.3. In the present case, it can be noted that, contrary to Section 2.3., the displacement and strain fields are not homogeneous. Figure 11a shows the displacement field on the surface of the specimen just before the failure of the specimen. One can note the good symmetry of the displacement field about the two loading directions.

\subsection{Analysis of the Shear Experiment by the DIC Technique Coupled With FE Simulations}

To analyze the experimental results, two different approaches are developed. On the one hand, one uses all the experimental points within the ROI (i.e., all the centers of the ZOIs). The strain field is directly deduced from the measured displacement field by a numerical derivation. The damage post-processor is subsequently used to compute damage maps in the plies. On the other hand, one uses only the information on the boundary of the ROI. The displacements of these points are then used as boundary conditions for a FE computation. As a first approximation, an elastic (orthotropic) computation is performed and followed by a post-processing analysis to obtain the damage field. Figures 11b-c show the strain fields computed for the last image before failure. The strain field maps obtained by the two approaches are similar. Its symmetry with respect to the loading axes validates the quality of the applied loading. The extreme strain levels

are comparable: the minimum is of the order of $-10^{-2}$ and the maximum of the order of $-10^{-3}$. This a posteriori result confirms the FE computations used to design this specimen geometry and the fact that the central part of the specimen plays a key role in this shear experiment. However, one can note that the strain field evaluated with the full-field displacement measurement is more heterogeneous than the one computed by using the measured displacement boundary conditions. This is a first indication that the material is not homogeneous on the scale of the measurements (of the order of 2-3 $\mathrm{mm}$ ). It is worth remembering that the errors related to the correlation technique are negligible for strains of the order of $10^{-2}$. Therefore, it can be stated that the strain field fluctuations are induced by material imperfections.

As mentioned earlier, the damage fields can be used to predict the onset of failure related to the degradations in both plies. The damage field inside each layer within the ROI is obtained by a computation by using the above-mentioned damage post-processor. Figure 12 shows shear damage fields $\left(\mathrm{d}_{12}\right)$ in the $+45^{\circ}$ and $-45^{\circ}$ plies. The fields obtained by the two approaches are again similar. As anticipated by the a priori computations (Fig. 9b), shear damage increases more in the central part of the specimen than near the edges. The damage field computed with the first 
approach is more irregular. This field indicates a high degradation of the matrix, even more important (i.e., 0.6) than that observed in a tensile test at $\pm 45^{\circ}$ (i.e., 0.5). However, this damage field does not correspond to the actual failure pattern (Fig. 13c). Matrix damage is probably not the prevalent mechanism leading to the final failure of the specimen.

To predict failure, the relevant variable to consider is damage in the fibers $\left(\mathrm{d}_{1}\right)$, i.e., fiber breakage is likely to be the mechanism responsible for the final failure. Figures $13 a-b$ show the damage field for the two ply orientations. This time, the two approaches yield very different damage patterns. For the approach only using the measured boundary conditions, no significant degradation in the fiber directions is obtained within the ROI (i.e., $<0.25$ ). On the contrary, for the full-field approach, it can be noted that the analysis of the damage contours in both ply directions can reproduce the overall failure pattern (Figures 13c). This failure pattern is induced by the anisotropy of the material, and fiber breakage caused by the undulations of the fiber (Fig. 6a) on the scale of the measurements.

These results show that a damage meso-model is able to capture the overall failure pattern (i.e., damage maps in both ply directions) and to conclude that fibers in both directions are damaged at the inception of a macrocrack. It is also important to note that these conclusions can be drawn only thanks to a full-field strain measurement (on a macro scale) used as input to a post-processor to evaluate the damage variables on the ply level (i.e., on the meso scale). Therefore, this test constitutes a first validation of the damage model for a material on the scale of its use in practical applications.

\section{CONCLUSIONS}

It has been shown that digital image correlation is a well-suited technique for mechanical investigations. In particular, no special preparation of the surface is needed except for some applications that require a coating by a random black and white pattern. In addition, the technique is not very sensitive to the illumination of the specimen. From both theoretical analyses and experimental comparisons with conventional strain gauges, the resolution of the technique is shown to be equal to $510^{-5}$ for strains by using an 8-bit CCD camera.

Interactions between experimental data and mechanical investigations are then discussed on the design of a shear experiment on a $\mathrm{C} / \mathrm{C}$ composite material. The full displacement field has been considered in a numerical simulation to derive experimental strain field. A damage post- 
processor has been applied to the experimental results to compute different damage fields. The approach is able to reproduce the observed failure pattern caused by fiber breakage in the experiment. A full-field assessment was needed to account for material heterogeneities on the scale of the observations.

Even though the present technique is suitable for planar surfaces, it can be noted that it is also applicable to cylinders when the radius is not too small in comparison with the size of the region of interest. ${ }^{37}$ The present digital image correlation technique was also used to monitor a high temperature thermomechanical experiment on aluminum tubes for which the texture was simply created by high temperature black and white paint. ${ }^{38}$ Even higher temperatures can be reached by using black and white ceramic powders. ${ }^{24}$

\section{ACKNOWLEDGEMENTS}

The authors wish to acknowledge the help of Pierre Renaud the tensile tests on the aluminum alloy and Michel Coret for his assistance during the development of the DIC routine. The SNECMA Engine Division provided the Multirex ${ }^{\circledR} \mathrm{C} / \mathrm{C}$ composite. 


\section{REFERENCES}

1. Desrues, J., Lanier, J. and Stutz, P., "Localization of the Deformation in Tests on Sand Sample,” Engng. Fract. Mech., 21 (4), 909-921 (1985).

2. Lagarde, A. (Ed.), Proc. IUTAM Symposium on Advanced Optical Methods and Applications in Solid Mechanics (Kluwer, the Netherlands), (2000).

3. Humbert, L., Valle, V. and Cottron, M., "Experimental Determination and Empirical Representation of Out-of-Plane Displacements in a Cracked Elastic Plate Loaded in Mode I," Int. J. Solids Struct., 37, 5493-5504 (2000).

4. Sutton, M.A., McNeill, S.R., Helm, J.D. and Chao, Y.J., "Advances in Two-Dimensional and Three-Dimensional Computer Vision," in Photomechanics, P.K. Rastogi (Ed.), Topics in Appl. Phys., 77, 323-372 (2000).

5. Roux, S., Hild, F. and Berthaud, Y., "Correlation Image Velocimetry: A Spectral Approach," Appl. Optics (2001), in press.

6. Choi, D., Thorpe, J.L. and Hanna, R., "Image Analysis to Measure Strain in Wood and Paper," Wood Sci. Technol., 25, 251-262 (1991).

7. G'Sell, C., Hiver, J.-M., Dahnoun, A. and Souahi, A., "Video-Controlled Tensile Testing of Polymers and Metals Beyond the Necking Point," J. Mat. Sci. , 27, 5031-5039 (1992).

8. Chevalier, L., Calloch, S., Hild, F. and Marco, Y., "Digital Correlation used to Analyze the Multiaxial Behavior of Rubber-like Materials," Eur. J. Mech. A/Solids, 20, 169-187 (2001).

9. Dudderar, T.D. and Simpkins, P.G., "Laser Speckle Photography in a Fluid Medium," Nature 270, 45 (1977).

10. Pickering, C.J.D. and Halliwell, N.A., "Speckle Laser in Fluid Flows: Signal Recovery with Two-Step Processing," Appl. Opt., 23, 1129 (1984).

11. Merzkirch, W., Flow Visualization (Academic, New York, USA) (1987).

12. Rastogi, P.K. (Ed.), Photomechanics, Topics in Appl. Phys., 77, Springer, Berlin (Germany) (2000).

13. Chiang, F.P. (Ed.), "Coherent Optical Technique and Experimental Mechanics," Opt. Eng., 21 (3) (1982). 
14. Sutton, M.A., Wolters, W.J., Peters, W.H., Ranson, W.F. and McNeill, S.R., "Determination of Displacements Using an Improved Digital Correlation Method," Im. Vis. Comp., 1 (3), 133-139 (1983).

15. Chu, T.C., Ranson, W.F., Sutton, M.A. and Petters, W.H., "Applications of Digital-ImageCorrelation Techniques to Experimental Mechanics," EXPERIMENTAL MECHANICS, 3, 232244 (1985).

16. Mguil, S., Morestin, F. and Brunet, M., "Mesure des déformations par corrélation directe d'images numériques," Proc. Photomécanique 98, Berthaud, Y., Cottron, M., Morestin, F., Moucheront, P. and Taroni, M. (Eds.), GAMAC, Marne-la-Vallée (France), 361-368 (1998), in French.

17. Chen, D.J., Chiang, F.P., Tan, Y.S. and Don, H.S., "Digital Speckle-Displacement Measurement Using a Complex Spectrum Method,” Appl. Opt., 32, 1839 (1993).

18. Berthaud, Y., Scholz, J. and Thesing, J., "Méthodes optiques et acoustiques de mesures des caractéristiques mécaniques," Proc. Colloque national MECAMAT "Mécanismes et mécanique des grandes déformations," Aussois (France), 77-80 (1996), in French.

19. Chiang, F.P., Wang, Q. and Lehman, F., "New Developments in Full-Field Strain Measurements Using Speckles,” ASTM STP 1318, 156 (1997).

20. Bouvet, C., Calloch, S. and Lexcellent, C., "Mechanical Behavior of a Cu-Al-Be Shape Memory Alloy under Multiaxial Proportional and Nonproportional Loadings," J. Eng. Mat. Tech., submitted, (2001).

21. Berthaud, Y., Calloch, S., Collin, F., Hild, F. and Ricotti, Y., "Analysis of the Degradation Mechanisms in Composite Materials through a Correlation Technique in White Light," IUTAM symposium on Advanced Optical Methods and Applications in Solid Mechanics, Lagarde, A. (Ed.), Kluwer (the Netherlands), 627-634 (2000).

22. Wattrisse, B., Chrysochoos, A., Muracciole, J.-M. and Némoz-Gaillard, M., "Analysis of Strain Localization during Tensile Tests by Digital Image Correlation," EXPERIMENTAL MECHANICS, 29-39 (2001).

23. Berthaud, Y., Calloch, S., Cluzel, C., Hild, F. and Périé, J.-N., "Experiment / Computation Interactions by using Digital Image Correlation," Interferometry in Speckle light, Theory and Applications, Jacquot, P. and Fournier, J.-M. (Eds.), Springer, Berlin (Germany), 59-66 (2000) 
24. Hild, F., Périé, J.-N. and Coret, M., "Mesure de champs de déplacements 2D par intercorrélation d'images : CORRELI ${ }^{2 \mathrm{D}}$," internal report (LMT-Cachan), 230 (1999) in French.

25. Matlab 5.3, The MathWorks, inc. (http://www.mathworks.com) (1999).

26. Young, I.T., Gerbrands, J.J. and van Vliet, L.J., Image Processing Fundamentals, http://www.ph.tn.tudelft.nl/Courses/FIP, (1999).

27. Hild, F., Dispositif de traction-compression d'une éprouvette. ENS de Cachan / Renault, French patent no. 9006848 (Bulletin Officiel de la propriété industrielle, 92/33 14 août 1992, n de publication 2662801$)$, June $1^{\text {st }},(1990)$.

28. Hild, F., Amar, E. and Marquis, D., "Stress Heterogeneity Effect on the Strength of Silicon Nitride,” J. Am. Ceram. Soc., 75 (3), 700-702 (1992).

29. Ladevèze, P. and Ledantec, E., "A Damage Modelling of the Elementary Ply for Laminated Composites,” Comp. Sci. Tech., 43, 257-267 (1992).

30. Périé, J.-N., Aubard, X., Cluzel, C. and Ladevèze, P., "Méso-modélisation des mécanismes d'endommagement d'une famille de matériaux Sepcarb ${ }^{\circledR}$ à textures multidirectionnelles”, Proc. JNC11, AMAC, 883-888 (1998) in French.

31. Ladevèze, P., "sur la mécanique de l'endommagement des composites," Proc. JNC 5, Bathias, C. and Menkès, D. (Eds.), Pluralis Publication, Paris (France), 667-683 (1986) in French.

32. Périé, J.-N., "Méso-modélisation des mécanismes d'endommagement dans les composites $\mathrm{C} / \mathrm{C}$ à texture multidirectionnelle," PhD dissertation, ENS de Cachan (2000) in French.

33. Ladevèze, P., Allix, O. and Cluzel, C., "Damage modelling at the macro and meso scales for 3D composites," Damage in Composite Materials, Voyiadjis, G. Z. (Ed.), Elsevier, 195-215 (1993).

34. Gasser, A., Ladevèze, P. and Peres, P., "Damage modelling for a laminated ceramic composite,” Mat. Sci. Eng., A250, 249-255 (1998).

35. Aubard, X., Cluzel, C., Ladevèze, P. and Périé, J.-N., "Méso-modélisation des matériaux composites carbone/carbone à texture Multirex", Proc. $3^{\mathrm{e}}$ colloque national en calcul des structures, 863-869 (1997) in French.

36. Cluzel, C., "DAMLAM : un outil simplifié pour l'analyse de composites stratifiés”, Proc. JNC12, AMAC, 245-254 (2000) in French. 
37. Lu, H., Vendroux, G. and Knauss, G., "Surface Deformation Measurements of a Cylindrical Specimen by Digital Image Correlation,” EXPERIMENTAL MECHANICS, 433439 (1997).

38. Pommier, B., Charkaluk, E. and Hild, F., "Analyse d'un essai de fatigue thermique par corrélation d'images," Proc. Photomécanique 2001, Berthaud, Y., Cottron, M., Dupré, J.-C., Morestin, F., Orteu, J.-J. and Valle, V. (Eds.), 359-366 (2001) in French. 


\section{FIGURE CAPTIONS}

Figure 1: ZOI in the initial (a) and 'deformed' (b) image.

Figure 2: flowchart of the sub-pixel correlation algorithm.

Figure 3: Average relative error between measured and prescribed displacements vs. prescribed displacement for different digitizations of an artificial 1D signal.

Figure 4: Measured vs. prescribed displacement for an 8-bit camera. The reference image is shown in Fig. 10a.

Figure 5: Strains measured by gauges and predicted by digital image correlation (DIC) with two ZOI sizes in a tensile test on an aluminum specimen loaded in tension.

Figure 6: View of the material microstructure (a) and a shear experiment on a composite plate (b).

Figure 7: Predicted (dashed line) versus experimental (solid line) stress/strain curves for tensile tests on a $\mathrm{C} / \mathrm{C}$ composite at $0^{\circ}$ (a) and $\pm 45^{\circ}$ (b).

Figure 8: Multiaxial testing machine ASTREE (a) and schematic of the centroid control system for one axis (b).

Figure 9: Schematic of the shear experiment (a) and shear damage contours in one quarter of either ply of the specimen (b).

Figure 10: Location of the strain gauges (white rectangles) and region of interest for the DIC analysis (a), comparison between two gauge responses and measurements by the DIC technique (b), load history (c) in a shear experiment on a $\mathrm{C} / \mathrm{C}$ composite.

Figure 11: Displacement map prior to failure (a). An amplification factor of 30 is used for the inplane displacement vectors. Strain $\varepsilon_{22}$ maps deduced from: (b) a full-field displacement 
measurement and a direct strain derivation, (c) the measured boundary conditions and an elastic computation.

Figure 12: Matrix damage contours $d_{12}$ in both ply directions predicted by the damage postprocessor using strains deduced from: (a) a full-field displacement measurement and a direct derivation, (b) the measured boundary conditions and an elastic computation.

Figure 13: Fiber damage contours $d_{1}$ in both ply directions predicted by the damage postprocessor using strains deduced from: (a) a full-field displacement measurement and a direct derivation, (b) the measured boundary conditions and an elastic computation. Final failure pattern (c). 


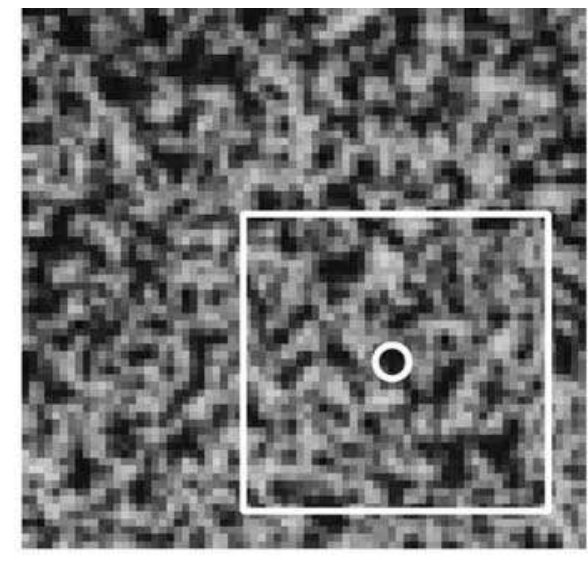

-a-

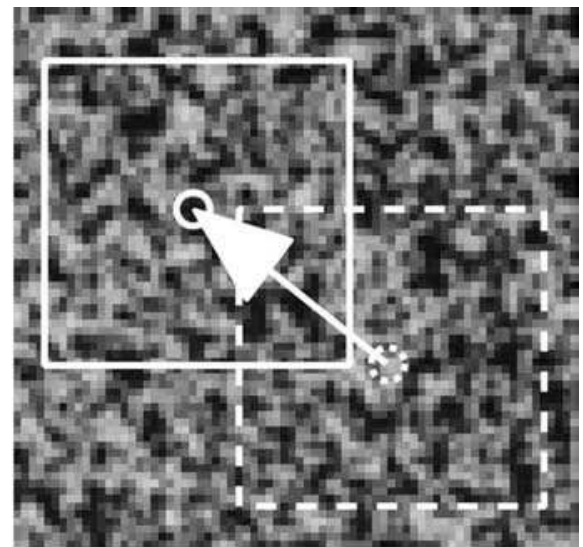

-b-

Figure 1 


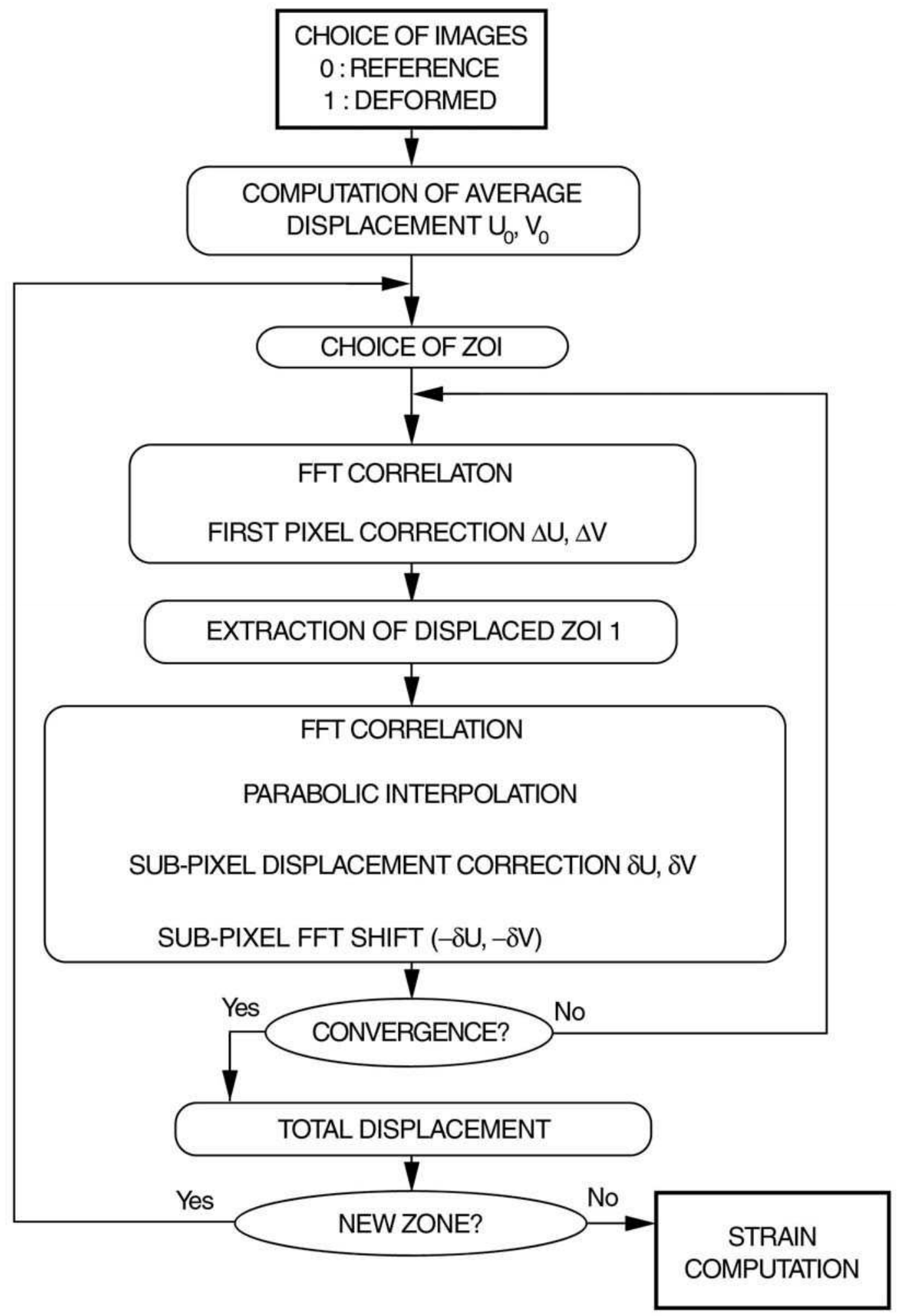

Figure 2 


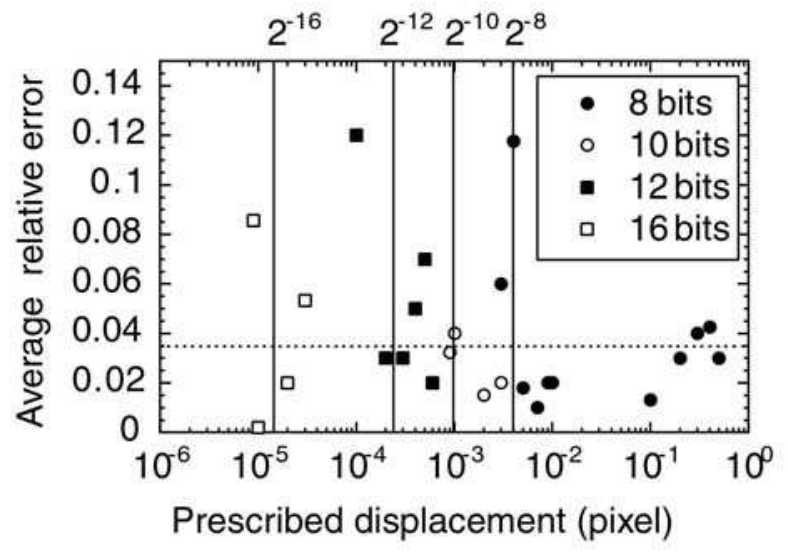

Figure 3 


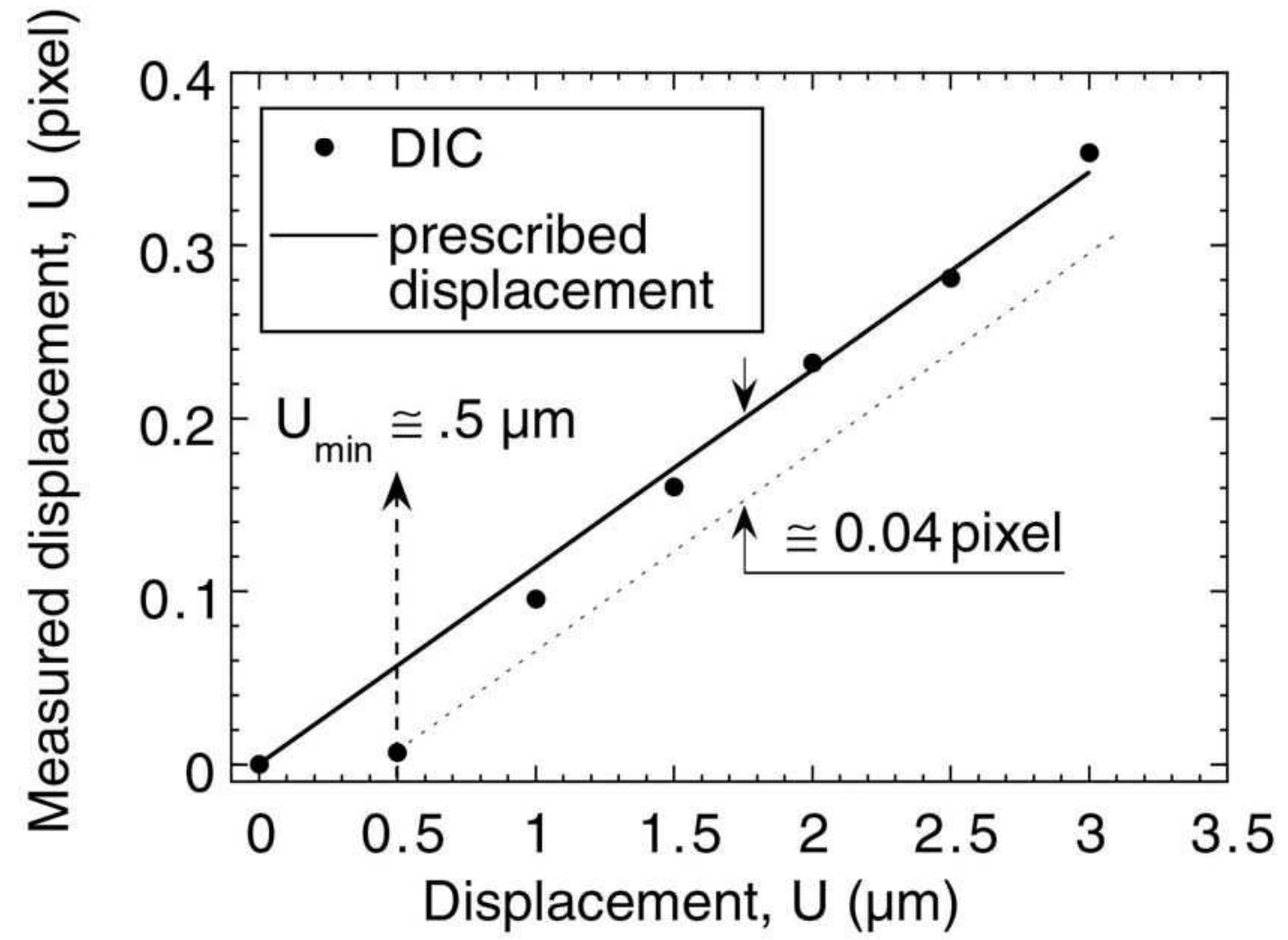

Figure 4 


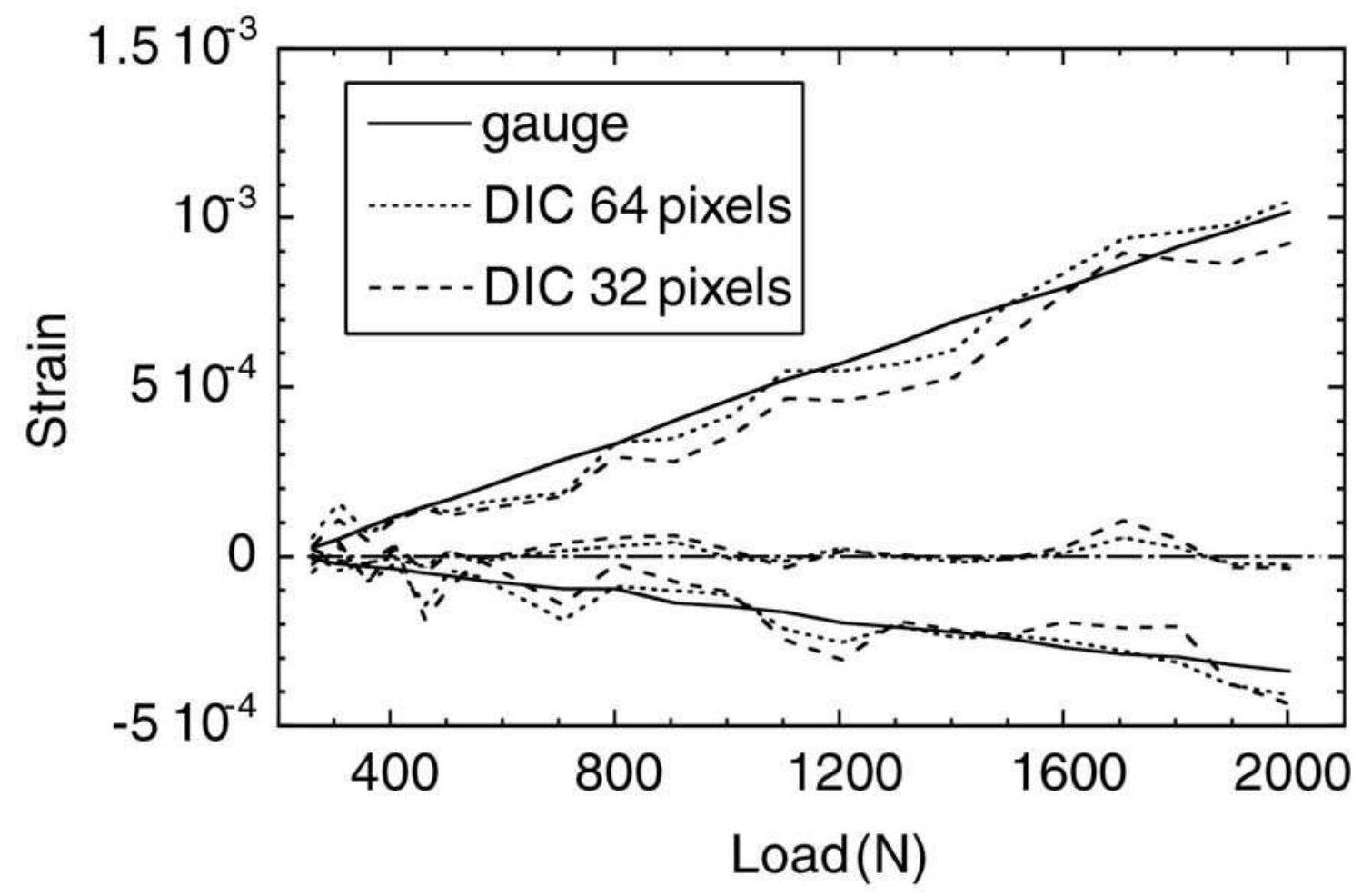

Figure 5 


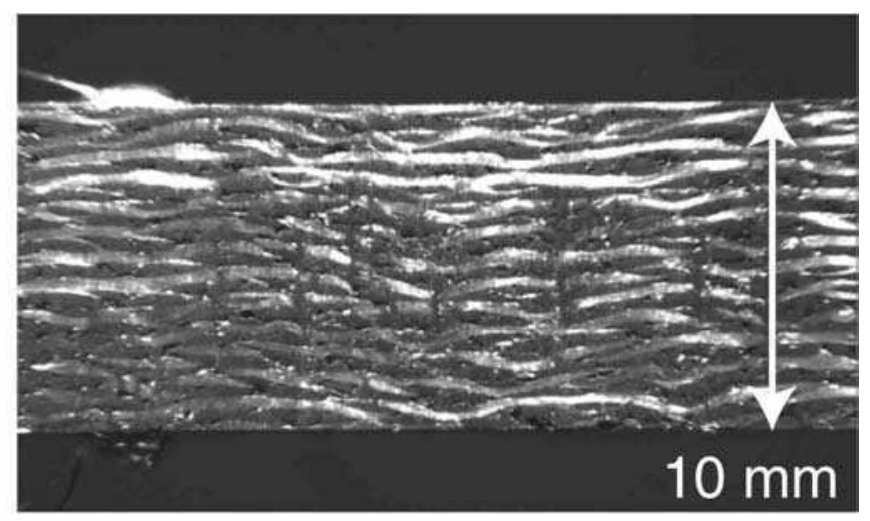

-a-

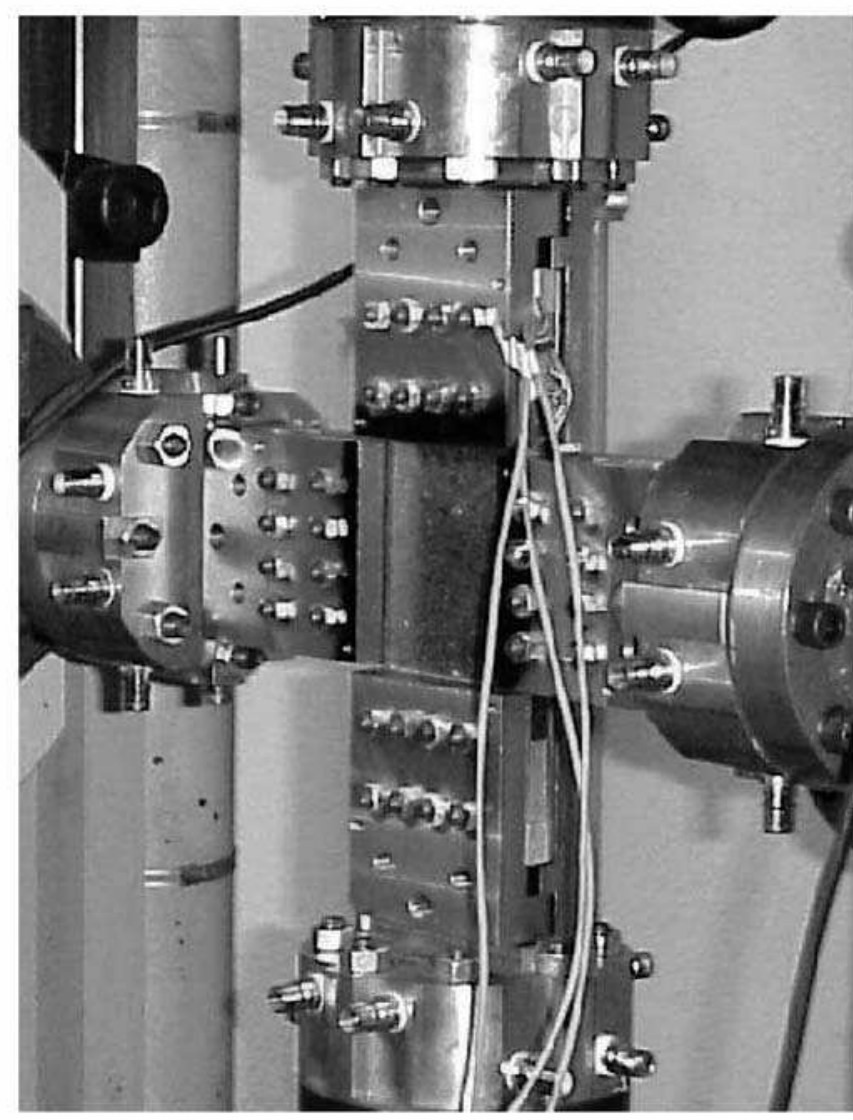

-b-

Figure 6 